\title{
The vagus nerve mediates the stomach-brain coherence in rats
}

\author{
Jiayue Cao ${ }^{1}$, Xiaokai Wang ${ }^{1}$, Jiande Chen ${ }^{3}$, Nanyin Zhang ${ }^{4}$, Zhongming Liu* ${ }^{* 1,2}$ \\ ${ }^{1}$ Department of Biomedical Engineering, University of Michigan, Ann Arbor, USA \\ ${ }^{2}$ Department of Electrical Engineering and Computer Science, University of Michigan, Ann \\ Arbor, USA \\ ${ }^{3}$ Division of Gastroenterology and Hepatology, University of Michigan, Ann Arbor, USA \\ ${ }^{4}$ Department of Biomedical Engineering, Huck Institutes of the life sciences, Pennsylvania State \\ University \\ * Correspondence \\ Zhongming Liu, Ph.D. \\ Associate Professor \\ Room 2119, Carl A Gerstacker Building \\ 2200 Bonisteel Blvd. \\ Ann Arbor, Ml 48109 \\ Phone: (734)764-2073 \\ Email: zmliu@umich.edu
}




\section{Abstract}

Interactions between the brain and the stomach shape both cognitive and digestive functions. Recent human studies report spontaneous synchronization between brain activity and gastric slow waves in the resting state. However, this finding has not been replicated in any animal models. The neural pathways underlying this apparent stomach-brain synchrony is also unclear. Here, we performed functional magnetic resonance imaging while simultaneously recording bodysurface gastric slow waves from anesthetized rats in the fasting vs. postprandial conditions and performed a bilateral cervical vagotomy to assess the role of the vagus nerve. The coherence between brain fMRI signals and gastric slow waves was found in a distributed "gastric network", including subcortical and cortical regions in the sensory, motor, and limbic systems. The stomachbrain coherence was largely reduced by the bilateral vagotomy and was different between the fasting and fed states. These findings suggest that the vagus nerve mediates the spontaneous coherence between brain activity and gastric slow waves, which is likely a signature of real-time stomach-brain interactions. However, its functional significance remains to be established. 


\section{Introduction}

The stomach and the brain interact with one another. The brain regulates food ingestion and digestion (Konturek et al., 2004; Holtmann and Tally, 2014; Clemmensen et al., 2017). The stomach affects intuition, emotion, and cognition (Mayer, 2011; Klarer et al., 2014, 2018). Such interactions are partly mediated by bidirectional neural signaling along the so-called stomachbrain neuroaxis (Powley et al., 2019; Liu et al., 2018; Kaelberer et al., 2018; Levinthal and Strick, 2020; Browning and Travagli, 2014; Holtmann and Talley, 2014). It includes neural circuits and pathways in both peripheral and central nervous systems (Powley et al., 2019; Mayer et al., 2019; Rebollo et al., 2021).

Prior studies typically characterize the stomach-brain neuroaxis by applying stimulation to the stomach or the brain while recording the resulting brain or gastric responses, respectively. For example, gastric distention can activate the subcortical and cortical networks involved in processing gastric sensation (Ladabaum, 2001; Mayer et al., 2019; Wang et al., 2008; Vandenbergh et al. 2005; Stephan et al., 2003). Gastric electrical stimulation can activate brainstem nuclei and cortical regions and reveal their functional selectivity (Cao et al., 2019; 2021). Likewise, brain stimulation can also modulate gastric motor function (Lyubashina, 2004; Hurley-Gius and Neafsey, 1986). Although these studies offer valuable insights, the stimulation settings used are often artificial, narrowly focused, prone to physiological confounds, and atypical of natural interactions between the stomach and the brain.

Recent studies demonstrate spontaneous interactions between brain activity and gastric electrical activity (Rebollo et al., 2018; Rebollo and Tallon-Baudry, 2021; Choe et al., 2021; Richter et al., 2017; Todd et al., 2021). In their seminal work, Rebollo et al. reports that resting state brain activity observed with functional magnetic resonance imaging (fMRI) is phase locked with gastric slow waves observed with electrogastrography (EGG) (Rebollo et al., 2018). This finding has been replicated by their follow-up study (Rebollo et al., 2021) and an independent 
group (Choe et al., 2021). In human brains, the stomach-brain synchrony is most pronounced in sensorimotor areas, default-mode network, and cerebellum (Rebollo et al., 2018; Choe et al., 2021) and likely extends further to other networks or systems. In addition, the phase of gastric slow waves is coupled with the amplitude of alpha oscillations in magnetoencephalography (MEG) (Richter et al., 2017) and electroencephalogram (EEG) (Todd et al., 2021), suggesting that the brain activity coupled with gastric activity is of neural origin.

It is also unclear how brain and gut rhythms are synchronized in real-time despite a long distance. The vagus is central to how the brain modulates gastric motor function, such as gastric tone (Azpiroz and Malagelada, 1987), accommodation (Takahashi and Owyang, 1997), motility, and emptying (Lu et al., 2018, 2020), primarily through the dorsal vagal complex in the brainstem or namely the vagovagal reflexes (Powley et al., 2019; Travagli and Anselmi, 2016; Harper et al., 1959; Shapiro and Miselis, 1985; Roger et al., 1995,1996). The dorsal vagal complex interacts with the hypothalamus, thalamus, amygdala, insular cortex, medial prefrontal cortex, and sensorimotor cortex (Browning and Travagli, 2014; Rinaman and Schwartz, 2004; Han et al., 2018; Levinthal and Strick, 2020; Mayer et al., 2019). Moreover, a subtype of vagal afferent receptors, namely intramuscular arrays (Berthoud and Powley 1992; Brookes et al., 2013), directly innervate interstitial cells of Cajal (ICCs) (Powley et al., 2019). The ICCs initiate the slow wave and pace the stomach (Cajal 1893; Sanders et al., 1996). Taken together, the vagal pathways and their extension in the brain are plausible substrates that bring widespread brain activity into partial synchronization with gastric slow waves.

Here, we hypothesize that the vagal nerves mediate the stomach-brain synchrony in the resting state. We acquired EGG and fMRI simultaneously in rats and evaluated their coherence at the frequency of the gastric slow wave in an attempt to replicate the findings in prior human studies (Rebollo et al., 2018; Choe et al., 2021). Importantly, the use of animal models allowed us to apply bilateral vagotomy and assess its effects on the apparent stomach-brain synchrony. In addition, we also tested the effect of fasting vs. fed (postprandial) states. 


\section{Methods and Materials}

\section{Animals}

A total of 18 Sprague-Dawley rats (male, 250-350 g, Envigo RMS, Indianapolis, IN) were used in this study. All animals were housed in a controlled environment with a temperature at 21 $\pm 1^{\circ} \mathrm{C}$ and light on from $6 \mathrm{AM}$ to $6 \mathrm{PM}$. After diet training and overnight fasting, the animals were divided into three groups for simultaneous acquisition of $\mathrm{fMRI}$ and $\mathrm{EGG}$ under three different conditions: fed with intact vagal nerves $(n=8)$ or vagotomy $(n=5)$, or fasting with the intact vagus $(n=5)$. All animal procedures followed a protocol approved by the Institutional Animal Care and Use Committee and the Laboratory Animal Program at Purdue University.

\section{Animal preparation}

Through diet training, every animal was preconditioned to be able to voluntarily consume a test meal before the experiment. The test meal was a fixed quantity $(5 \mathrm{~g})$ of dietgel (DietGel Recovery, ClearH2O, ME, USA). The test meal had $5.6 \mathrm{kcal}$, containing $0.03 \mathrm{~g}$ protein, $1.16 \mathrm{~g}$ carbohydrates, $1 \mathrm{~g}$ sugars, $0.055 \mathrm{~g}$ dietary fibers, $0.095 \mathrm{~g}$ fat, and $0.01 \mathrm{~g}$ saturated fat. As described elsewhere (Lu et al., 2017), the diet training took about 5 days. In the first two days, 56 g dietgel was placed in the animal cage together with regular chow. In the next three days, the animal was first fasted for 18 hours from 6 PM to 12 PM on the next day and fed only with dietgel $(56 \mathrm{~g})$ at $12 \mathrm{PM}$. The animal was allowed to eat the dietgel from $12 \mathrm{PM}$ to $6 \mathrm{PM}$; until then it was fasted again for the next day.

After diet training, all animals were fasted overnight. Food was removed from the cage at $6 \mathrm{PM}$ to prepare the animal for the experiment starting at about $12 \mathrm{PM}$ the next day. One group of animals (fasted, $n=5$ ) remained fasted during the experiment. Other animals $(n=13)$ were provided a $5 \mathrm{~g}$ test meal (dietgel) and were able to quickly consume the meal at the beginning of 
the experiment. Among those that consumed the test meal, one group of animals had additional vagotomy $(n=5)$ whereas the rest had an intact vagus $(n=8)$. The animals were anesthetized for the vagotomy (if applicable), electrode placement, and fMRI-EGG acquisition in that order.

\section{Anesthesia}

Every animal was initially anesthetized using an induction chamber with $5 \%$ isoflurane mixed in oxygen delivered at $1 \mathrm{~L} / \mathrm{min}$ for up to 5 minutes. Then the animal was transferred to a surgical bench, where $1.5-2.5 \%$ isoflurane mixed in oxygen was administered at $1 \mathrm{~L} / \mathrm{min}$ through a nose cone during surgical vagotomy (for 5 animals after the test meal) and placement of EGG electrodes (for all 18 animals). Then the animal was transferred to a rat holder placed in the MRI scanner and was set up to receive isoflurane through a nose cone and dexdomitor (zoetis, Parsippany-Troy Hills, New Jersey, USA) through subcutaneous infusion. When the animal was set up for MRI, isoflurane was delivered at up to $0.5 \%, 1 \mathrm{~L} / \mathrm{min}$ and a bolus of the dexdomitor $(12.5 \mu \mathrm{g} / \mathrm{Kg}, 0.05 \mathrm{mg} / \mathrm{ml})$ was administered through subcutaneous injection. About 15 minutes later, continuous subcutaneous infusion of the dexdomitor started at $12.5 \mu \mathrm{g} /(\mathrm{Kg}$ x hour) and 0.05 $\mathrm{mg} / \mathrm{ml}$, while isoflurane was reduced to $0.1-0.5 \%$. Following that, the infusion rate of the dexdomitor was increased by $12.5 \mu \mathrm{g} /$ ( Kg x hour) for every additional hour to maintain a stable physiological condition over the course of fMRI-EGG acquisition. That is, the heart rate at 250350 beats per minute, the respiratory rate at $20-60$ times per minute, SpO2 above $96 \%$, and the rectal temperature at $36.5-37.5 \mathrm{C}^{\circ}$. These physiological parameters were monitored using two systems: Pulse Oximeter and Rat \& Mouse Heart Rate Monitor Module (mouseSTAT, Kent scientific, Torrington, CT, USA), and the monitoring and gating system for small animals (model1030, SA instruments, Stony Brook, NY, USA). A heating pad was also controlled to keep the animal warm inside the MRI scanner. 


\section{Vagotomy}

Bilateral cervical vagotomy was performed in a group of $(n=5)$ animals after they consumed the test meal. The surgery was performed when the animal was anesthetized with 1.5$2.5 \%$ isoflurane as described above. After a toe pinch test, the fur in the cervical area was shaved, followed by scrubbing the skin with $75 \%$ ethanol and betadine. Then, a $2-3 \mathrm{~cm}$ midline incision was made, starting from the jawline and moving caudally. Skin and soft tissue were separated for the (left or right) cervical vagus nerve to be exposed, isolated and cut. This procedure was performed first for the left side and then for the right side, resulting in bilateral cervical vagotomy. The incision was sutured closed to make the animal ready for attachment of EGG electrodes on the abdominal surface (as described in the next subsection).

\section{Placement of body-surface electrodes}

For all animals, an array of electrodes was attached to the abdominal surface for EGG recordings. The fur on the abdominal skin surface was carefully shaved. We also applied hair remover lotion and waited for $5 \mathrm{~min}$ and then removed the extra fur. The shaved skin was further cleaned with sterile saline to prepare for electrode attachment. The electrodes were a 5-by-6 array on a thin $45 \times 60 \mathrm{~mm}^{2}$ perylene substrate (chronic EMG patch, Microprobes, Gaithersburg, MD, USA). Each electrode in the array was a $1 \times 2 \mathrm{~mm}^{2}$ platinum contract, with the distance between adjacent electrodes of $7 \mathrm{~mm}$. The array was attached to the skin surface and sutured at four corners and four edges. Additional skin tape was applied to further secure the electrode attachment. In the array, the rows were aligned from left to right and the columns were aligned from superior to inferior (Figure 1A). The intersection of the second row and the third column was on top of the xiphoid. In addition, two adhesive carbon electrodes (Neotech, Valencia, CA, USA) were used as the reference and the ground for EGG, respectively. The reference was about 5 $\mathrm{mm}$ superior to the xiphoid on the central line. The ground was on the left hind limb. 


\section{EGG recording}

The cutaneous EGG signals were recorded using an electrophysiology system (Tucker Davis Technologies, Alachua, FL, USA) while the animal was placed inside the MRI scanner during concurrent fMRI (see details in the next subsection). The electrodes were connected via $\mathrm{Pt} / \mathrm{Ir}$ wires and an Omnetics 36 socket nano connector to a headstage (LP32CH-Z-32 Channel Chronic Headstage, Tucker Davis Technologies, Alachua, FL, USA) near the animal. The headstage was connected via a shielded copper cable to an amplifier (PZ5 NeuroDigitizer, Tucker Davis Technologies, Alachua, FL, USA) placed in the MRI room. The amplifier digitized the signals (sampling rate: $24 \mathrm{kHz}$; bandwidth: $\mathrm{DC}$ to $24 \mathrm{kHz}$; dynamic range: +/-500mV; ADC resolution: 28 bits) and connected to a data acquisition system (RZ2 BioAmp processor, Tucker Davis Technologies, Alachua, FL, USA) outside the MRI room through an optical fiber. The data acquisition system also received and stored a TTL trigger from MRI to synchronize EGG and fMRI acquisition.

\section{MRI and fMRI acquisition}

FMRI was performed with the 7-tesla small-animal MRI system (BioSpec 70/30, Bruker, Billerica, MA, USA) with a volume transmit coil ( $86 \mathrm{~mm}$ inner diameter) and a quadrature surface receive coil. Each animal was placed on a rat holder in the prone position. The head was fixed with two ear bars and a bite bar. The brain's structure was acquired using a 2-D rapid acquisition with relaxation enhancement sequence with the repetition time $(T R)=5804.6 \mathrm{~ms}$, effective echo time $(T E)=32.5 \mathrm{~ms}$, echo spacing $=10.83 \mathrm{~ms}$, voxel size $=0.125 \times 0.125 \times 0.5 \mathrm{~mm}^{3}, \mathrm{RARE}$ factor $=8,50$ slices, and flip angle $(F A)=90^{\circ}$. FMRI was acquired using a 2-D single-shot gradientecho (GE) echo-planar imaging $(E P I)$ sequence with $T R=1 \mathrm{~s}, \mathrm{TE}=16.5 \mathrm{~ms}$, the number of repetition $=1,800$, in-plane resolution $=0.5 \times 0.5 \mathrm{~mm}^{2}$, slice thickness $=1 \mathrm{~mm}, 25$ slices, $\mathrm{FA}=55^{\circ}$, and duration $=30$ minutes. Each animal in the fed state (with or without vagotomy) underwent 
two sessions of fMRI, whereas each animal in the fasted state underwent four sessions of fMRI. The total time of fMRI-EGG acquisition was up to 2 hours in every animal.

\section{EGG preprocessing}

The high sampling rate and broad bandwidth of the EGG recording system allowed for complete separation of MRI-induced artifacts and EGG signals in the frequency domain without any confounding aliasing. Specifically, the signal recorded at each channel was first demeaned and then detrended by regressing out the 5th-order polynomial function that spanned the 30-min duration of each session. A low-pass filter was applied to the detrended signal with the cut-off frequency at $0.45 \mathrm{~Hz}$. The signal was resampled at $1 \mathrm{~Hz}$ such that EGG and fMRI shared the same sampling frequency. Although data was recorded from an array of electrodes, analysis in this paper focused on one electrode located at the intersection of the second row and the third column of the array (Figure 1A). Choosing this electrode as the channel of interest was because it was above the antrum of the stomach with peristaltic contractions (Lu et al., 2017). Among all electrodes, the location of this electrode was also most consistent across animals, since it was intentionally positioned to be on top of xiphoid in every animal.

\section{fMRI preprocessing}

The fMRI data was pre-processed using FSL (Jenkinson, et al., 2012), AFNI (Cox, 1996), and in-house software developed in MATLAB. Specifically, we first performed motion correction by registering the fMRI volumes from individual time points to the first volume using $3 d v o l r e g$ in AFNI. The first 10 volumes were then discarded to avoid a non-steady state of MR signal. The timing of every slice within each volume was corrected using slicetimer in FSL. To align fMRI data to the rat brain template (Valdes Hernandez et al., 2011), fMRI images were aligned to T2w anatomical images from the same animal using flirt in FSL, the T2w images were transformed to the template using fnirt in FSL, and applying the same transformation to the fMRI images 
coregistered individual animals' fMRI data to the same template. The coregistered fMRI signals were further denoised by regressing out the head-motion parameters and a 3rd-order polynomial fit of the slow drift. Lastly, data were spatially smoothed with a 3-D Gaussian kernel with a 0.5$\mathrm{mm}$ full-width at half maximum (FWHM).

\section{EGG-fMRI coherence}

Coherence between EGG and fMRI signals was evaluated at the dominant frequency of gastric slow waves. The slow-wave frequency was identified separately for each animal every 4 minutes to account for its variation across rats and over time. The slow-wave frequency was determined as the frequency with the greatest power spectral density between 0.06 and $0.13 \mathrm{~Hz}$. This frequency range was reasonable since gastric slow waves were expected to be around 5 cpm (or $0.083 \mathrm{~Hz}$ ) for rats (Tümer et al., 2008). We excluded data from the coherence analysis when the slow-wave frequency was outside the range of $0.06-0.13 \mathrm{~Hz}$.

Coherence between EGG and fMRI signals was evaluated at the slow-wave frequency. It was calculated as the power of the cross-spectral density normalized by the auto-spectral density as expressed in the following equation.

$$
C_{x y}(f)=\frac{\left|G_{x y}(f)\right|^{2}}{G_{x x}(f) G_{y y}(f)}
$$

where $x$ is the EGG signal, $y$ is the voxel-wise fMRI signal, $f$ is the slow-wave frequency, $G_{x y}(f)$ is the cross-spectral density, $G_{x x}(f)$ and $G_{y y}(f)$ are auto-spectral density, specifically evaluated at the frequency $f$. The resulting coherence, $C_{x y}(f)$, reflects the power transfer between $\mathrm{x}$ and $\mathrm{y}$. In the context of this study, the EGG-fMRI coherence measured the extent to which the gastric slow wave can predict or be predicted by brain activity at a voxel or region via linear systems. It can also account for the potential impact of the hemodynamic impulse response function on fMRI time series. 


\section{Statistical analysis}

The voxel-wise coherence was tested for significance by first converting it to a z score for each animal and then applying a one-sample t test to $z$ scores across animals. For each animal, the coherence measured at each voxel was compared against a null distribution, of which the samples were the coherence between randomly phase-shuffled EGG and fMRI signals. Phase shuffling of a signal kept the magnitude but altered the phase of its spectrum. After phase shuffling of EGG and fMRI signals, their coherence was disrupted and reduced to a chance level. The coherence of the original EGG and $\mathrm{fMRI}$ signals was compared to the null distribution and converted to a $z$ score by subtracting the mean and dividing by the standard deviation of the chance-level coherence. To test for the significance in the group level, a one-sample t test was voxel-wise applied to $z$ scores obtained from each group of animals (one-sided $p<0.01$ corrected with a cluster size greater than 10 voxels or $2.5 \mathrm{~mm}^{3}$ ).

The coherence with EGG was summarized with respect to anatomical regions of interest (ROIs). We used 156 ROls pre-defined according to the rat brain template and atlas. The ROls included cortical regions (Valdes Hernandez et al., 2011), subcortical regions or nuclei (Papp et al., 2014), and hand-drawn masks for the nucleus tractus solitarius (NTS) and subnuclei in the thalamus (Paxinos and Watson, 2006). For each ROI, the voxel-wise coherence with EGG (in terms of the $z$ score as described above) was first averaged within the ROI for each animal and then tested for significance across animals in the same group using a one-sample t test (with onesided $p<0.01$ and Bonferroni correction for multiple comparisons). The contrast between different groups, e.g., fed vs. fasted or vagal innervation vs. de-innervation, was tested for significance using two-sample t tests with two-sided $p<0.05$. 


\section{Results}

Prior studies suggested that the human brain had a gastric network, in which regional fMRI activity is phase-locked to the gastric slow wave - an intrinsic gastric rhythm at $0.05 \mathrm{~Hz}$ (Rebollo et al., 2018; Choe et al., 2021). Here, we asked whether rat brains had a similar gastric network, and if yes, whether and how this network relied on the vagal nerves that mediate stomach-brain interactions. To address these questions, we simultaneously acquired EGG and fMRI signals in 18 anesthetized rats and evaluated the EGG-fMRI coherence after they voluntarily consumed a $5 \mathrm{~g}$ test meal with either an intact vagus ("fed", $\mathrm{n=8}$ ) or bilateral cervical vagotomy ("vagotomy", $n=5$ ), or when they remained fasted ("fasted", $n=5$ ). The stomach-brain coherence measured in this way was compared between different conditions (vagal innervation vs. de-innervation and fed vs. fasted) to address whether and how the gastric network relied on intact vagal nerves and varied across gastric states.

\section{Rat brains also had a gastric network}

The slow waves recorded from anesthetized rats after consuming a test meal were 5.36 \pm 0.64 (average \pm standard deviation) $\mathrm{CPM}$ or $0.09 \pm 0.01 \mathrm{~Hz}$, in contrast to $\sim 3 \mathrm{CPM}$ (or $0.05 \mathrm{~Hz}$ ) in humans (Chen et al., 1999; Hamilton et al., 1986). We calculated the coherence between the EGG signal from a channel of interest above the antrum (Figure $1 \mathrm{~A}$ ) and the fMRI signal from every voxel in the post-prandial or fed state. See Figure 1B for exemplar EGG and fMRI signals.

In animals with intact vagal nerves, the fMRI signals were coherent with EGG at the slowwave frequency for $17 \%$ brain voxels (one-sided $p<0.005$, one-sample t test), highlighting a network involving both subcortical and cortical regions (Figure 1C). The brain network, herein referred to as the gastric network, covered the anterior cingulate cortex, insular cortex, medial prefrontal cortex, sensorimotor cortex, auditory and visual cortex, brainstem and cerebellum 
(Figure 1C). These regions were homologous to the human brain regions phase locked to gastric slow waves (Rebollo et al., 2018; Choe et al., 2021).

The gastric network was asymmetric between the two hemispheres. As shown in Figure $2 \mathrm{~A}$, the left hemisphere had more EGG-coherent regions than the right hemisphere. In the sensorimotor cortex, the EGG-fMRI coherence was spreaded across the cortical representations of multiple body parts, whereas the coherence was consistently weaker on the right hemisphere. In contrast, the right insular and auditory cortices were more coherent with EGG than their left counterparts (Figure 2B). The EGG-fMRI coherence tended to be lateralized to the left hemisphere for subcortical regions or nuclei, especially for the cerebellum.

These results suggest that rat brains also have a gastric network that manifests intrinsic coherence between EGG and fMRI signals, consistent with previous findings in human brains.

\section{EGG-fMRI coherence relied on vagal nerves}

We further attempted to identify the peripheral neural pathways underlying the apparent EGG-fMRI coherence. We chose to focus on the vagus nerve, which serves as the primary pathway for rapid and bi-directional neural interactions between the stomach and the brain (Travagli and Anselmi, 2016). Hence, we repeated the experiment in $(n=5)$ animals while applying bilateral cervical vagotomy before EGG-fMRI acquisition (Figure 1D). With bilateral vagotomy, the slow wave frequency was $4.95 \pm 0.57 \mathrm{CPM}$, and EGG-fMRI coherence significantly decreased but not completely diminished, while the coherence remained in the primary somatosensory cortex (Figure 1E).

The contrast between the conditions without vs. with bilateral vagotomy was evaluated to characterize the effects of the vagus on EGG-fMRI coherence (Figure 3). In the voxel level, bilateral vagotomy reduced the voxel-wise EGG-fMRI coherence in subcortical areas, such as the nucleus tractus solitarius, pontine reticular nucleus, medial globus pallidus, substantia nigra, thalamus, amygdala, and inferior colliculus, as well as fewer cortical regions in the left dysgranular 
insular and sensorimotor cortex (Figure 3A). Consistently on the ROI level, bilateral vagotomy significantly decreased the EGG-fMRI coherence $(p<0.05$, two-sample t test) for most regions in the gastric network (Figure 3B) whereas marginal but non-significant increases were found in fewer regions (Figure 3C).

These results suggest that the vagus is the primary (not necessarily the only) peripheral nerve that mediates the coherence between gastric and brain activities observed with EGG and fMRI respectively.

\section{EGG-fMRI coherence depended on gastric states}

For both rats and humans, the stomach shows continuous and peristaltic contractions in the post-prandial (fed) state and shows irregular and intermittent peristalsis (or migrating motor complex) in the fasted state (Deloose et al., 2012). We asked whether and how EGG-fMRI coherence depended on the fasted vs. fed state. To address this question, we repeated the same experiment in $(n=5)$ animals that remained fasted (after 18-hour fasting) during concurrent fMRIEGG acquisition. In the fasting state, the slow-wave frequency was $5.02 \pm 0.85 \mathrm{CPM}$. It was comparable with but slightly lower than the slow-wave frequency of $5.36 \pm 0.64$ CPM in the fed state (Figure 4A).

We assessed the EGG-fMRI coherence for the fasted state in the same way as for the fed state. In the fasted state, EGG-fMRI coherence was observed at brain regions (Figure 4B) that partially overlapped with those observed in the fed state (Figure 1C). To better appreciate their relationships, Figure 4C shows the intersection and complement of EGG-coherent voxels observed in the fed vs. fasted states. In regions with an overlap between the two states, the coherence with EGG was generally higher in the fed state than in the fasted state (Figure 4D). The ROI-level difference was significant in the primary somatosensory cortex, primary motor cortex, auditory cortex, olfactory nucleus, orbital cortex, septal nucleus, thalamic nuclei, agranular insular cortex, and nucleus of the solitary tract (two-sample t-test, $\mathrm{p}<0.05$ ). 
These results suggest that EGG-fMRI coherence exists in both fasted and fed states but tends to cover complementary subdivisions of a similar set of cortical and subcortical regions.

\section{Discussion}

Here, we present evidence for the coherence between brain activity observed with fMRI and gastric activity observed with EGG in rats. Our findings add to prior observations in humans (Rebollo et al., 2018; Choe et al., 2021) and shed light on an intrinsic gastric network with its hallmark feature being the EGG-fMRI coherence at the gastric pace-making frequency. The substantial reduction in the EGG-fMRI coherence by the bilateral vagotomy supports a primary role of the vagus. The alteration in the gastric network from the fasting to fed state suggests its functional relevance to different gastric conditions.

\section{Stomach-brain coherence}

It is only until recently that the spontaneous interaction between brain activity and gastric activity was studied in humans by simultaneously acquiring EGG along with fMRI (Rebollo et al., 2018; Choe et al., 2021), MEG (Richter et al., 2017), or EEG (Todd et al., 2021). Gastric slow waves were found to be coupled with the amplitude of posterior alpha oscillations (Richter et al., 2017; Todd et al., 2021) or the phase of resting state fMRI activities in sensory and motor cortices (Rebollo et al., 2018; Choe et al., 2020). Since posterior alpha oscillations are correlated with resting-state fMRI signals from sensory and motor cortices and the thalamus (Liu et al., 2012), gastric phase-amplitude coupling with posterior alpha oscillations and phase synchronization with fMRI signals are consistent findings suggesting that the human gastric network has its major components in sensory and motor areas (Rebollo and Tallon-Baudry, 2021).

Our study replicates prior human studies; however, several distinctions should be noted. Coherence used in this study and phase-locking value used in previous studies (Rebollo et al., 
2018; Choe et al., 2021) are similar measures of spectral coupling, except that coherence takes into account both amplitude and phase relationships, while the phase-locking value only reflects the phase relationship. Gastric slow waves are of a higher frequency in anesthetized rats $(\sim 0.08$ $\mathrm{Hz}$ ) than awake humans $(\sim 0.05 \mathrm{~Hz})$, approaching the higher limit of the physiological bandwidth of fMRI. Despite these methodological and physiological differences, the rat gastric network observed in this study covers similar regions as previously reported in humans, including the somatosensory cortex, motor cortex, visual cortex, auditory cortex, cerebellum, and insula cortex. This finding is also consistent with a previous study demonstrating that gastric electrical stimulation can induce both neural and fMRI responses in sensory and motor cortices even at frequencies up to $0.8 \mathrm{~Hz}$ (Cao et al., 2019). Together, results from this and prior studies suggest that EGG-fMRI coupling at the gastric slow-wave frequency is an intrinsic phenomenon possibly shared across different species.

Compared to the human gastric network, the EGG-fMRI coherence observed in rats covers more subcortical regions, including the nucleus tractus solitarius and nuclei in the basal ganglia, e.g., the globus pallidus, substantia nigra. These regions reside along the pathways between the autonomic nervous system and the limbic system (Albin et al., 1989; Browning and Travagli, 2014; Parent and Hazrati, 1995) and are likely involved in both autonomic control and emotion regulation (Andresen and Kunze, 1994; Pazo and Belforte, 2002; Pierce and Péron, 2020). In particular, the nucleus tractus solitarius in the brainstem receives vagal afferents that innervate the stomach and relays gastric information to the brain (Browning and Travagli, 2014; Powley et al., 2019).

\section{Supporting anatomical and functional evidence}

The EGG-coherent regions spread across multiple resting state networks in rats (Liang et al., 2011, 2012; Liu et al., 2020). Although the gastric network as a whole is not straightforward to interpret at this stage, most of its constituent regions reported herein have been shown to be 
structurally connected or functionally associated with the stomach. For example, neural tracing studies have shown that the insular cortex, medial prefrontal cortex, and cerebellum all receive gastric inputs and project to the stomach through polysynaptic connections (up to three synapses) (Browning and Travagli, 2014; Levinthal and Strick, 2020). The somatosensory and motor cortices project to the stomach (up to four synapses) via descending efferent pathways (Levinthal and Strick, 2020).

The involvement of visual and auditory cortex as well as hippocampus in the gastric network is supported by indirect functional evidence from the literature. During slow wave sleep, the firing rate of neurons in the visual cortex was found to be dependent on the phase of duodenal myoelectrical activity (Pigarev et al., 2013) or be responsive to both direct and transcutaneous stimulation of the gut (Pigarev et al., 1994, 2006). The fact that visual thalamus, e.g., lateral geniculate nuclei, receives direct projections from the brainstem, e.g., parabrachial nuclei, suggests a possible pathway for gastric signals to propagate to the visual cortex (Erişir et al., 1997; Uhlrich et al., 1988). Similarly, vagus nerve stimulation at the gastric branch or gastric electrical stimulation was found to modulate neural activity in the auditory cortex (Shetake et al., 2012; Engineer et al., 2015; Cao et al., 2019). Neurons in the hippocampus were also found to be activated by gastric distension or gastric electrical stimulation (Xu et al., 2008, 2009; Wang et al., 2006a, 2006b) likely for sensing satiety and regulating appetite (Davidson et al., 2007, 2009; Kanoski and Grill, 2017).

\section{Role of the Vagus in the stomach-brain synchrony}

Our results suggest that the vagus mediates the apparent stomach-brain synchrony. The neural mechanisms underlying the stomach-brain interaction involve both peripheral and central neural circuits. The peripheral component involves the vagus nerve and the splanchnic nerve. In general, the former is central to regulating gastric motor events (Travagli et al., 2006; Travagli and Anselmi, 2016), and the latter is more involved in visceral pain (Ness and Gebhalt, 1990). 
Bilateral cervical vagotomy abolishes both vagal afferent and efferent pathways that support vagovagal reflexes. The fact that the vagotomy largely diminished the EGG-fMRI coherence suggests that neural signaling along the vagus nerve is central to maintaining the synchrony between the brain and the stomach. The effects of vagotomy likely extend beyond the dorsal vagal complex, where vagal afferents end and efferents start, through connections between the dorsal vagal complex and other brain regions (Tsurugizawa et al., 2009). Also supporting the role of the vagus is the prior finding that vagus nerve stimulation could activate a similar set of brain regions as the regions highlighted in this study (Cao et al., 2017).

It is likely that intrinsic gastric rhythms are the source that causes brain activity to be synchronized with it. Gastric slow waves observed with EGG reflect an intrinsic rhythm that can be generated solely by the stomach itself. This intrinsic rhythm is thought to originate from and propagate through interstitial cells of Cajal (ICC) (Cajal 1893; Sanders et al., 1996), but likely involves other mechanisms as well (Yin and Chen, 2008; Sarna, 2008). ICCs within the circular and longitudinal layers of the stomach (ICC-IM) are innervated by vagal afferent nerves that branch into intramuscular arrays (Powley and Phillips, 2011; Powley et al., 2019), which serve as the receptors to transmit sensory information to the brainstem (Cao et al., 2021). The vagovagal circuitry in the brainstem may pass the gastric rhythm as the bottom-up input to other regions in the gastric network. Taken together, there is a plausible bottom-up pathway to allow intrinsic gastric rhythms to be passed to the brain and account for the apparent brain-stomach synchrony.

It is possible but less likely that brain activity controls the phase of gastric rhythm in order for the brain to be the cause of stomach-brain synchrony. Given the vagotomy, the rat stomach continued to generate a rhythmic gastric slow wave, despite a slightly lower frequency. Further evidence also suggests that the stomach maintains peristaltic contractions even after the bilateral vagotomy. Although the stomach receives inputs from sensorimotor cortical regions (Levinthal and Strick, 2020), there is no direct evidence suggesting that top-down neural inputs control the phase of the gastric slow wave. The vagal efferent nerves innervate gastric enteric neurons 
(Powley et al., 2019), which further innervate gastric smooth muscle cells (Furness et al., 2020).

It is not clear whether and how the brain controls the ICCs and gastric pace-making activity initiated by the ICCs. However, this does not imply that the brain does not influence EGG. As a gross measure of gastric electrical activity, EGG can result from any synchronized current sources from the stomach, including smooth muscle cells and ICCs. The brain may modulate the excitability of smooth muscle cells and their contributions to the amplitude of EGG, without directly influencing the frequency or phase presumably determined by ICCs. In line with this speculation, a previous study showed that the amplitude of EGG at its dominant frequency varies across different waking-to-sleep stages (Orr et al., 1997). We speculate that the brain senses gastric pace-making activity relayed through vagal afferent nerves, whereas the source of the synchronized rhythms is intrinsic to the gut, as opposed to the brain.

\section{Gastric mechanical versus electrical activity}

It should be noted that body-surface EGG may reflect both gastric pace-making activity and gastric contractions. The gastric pace-making activity is the electrical activity generated by ICCs; it remains largely stationary and continuous across all gastric states. In contrast, gastric contractions vary over time, being strong and continuous after a meal and becoming silent and intermittent in the fasting state (Sarna, 1985; Deloose et al., 2012; Abell 1988; Brandstaeter, et al., 2019; Kim and Malagelada, 1986). The presence of EGG-fMRI coherence in the fasting state suggests that gastric pace-making activity alone may cause the stomach-brain synchrony.

However, gastric contractions may also influence the stomach-brain synchrony, since the pattern of EGG-fMRI coherence was different between the fasting and fed states. However, it is not straightforward to fully disentangle how gastric pace-making activity and contractions cause the stomach-brain synchrony within the scope of this study, because they are often coupled and their coupling are influenced by extrinsic neural control. Addressing this question would ideally 
require simultaneous electromechanical recordings by placing both mechanical and electrical sensors on the stomach surface during concurrent fMRI. Another way is to attempt to separate electrical slow waves attributed to ICCs and myoelectric activity attributed to muscle cells (Kim and Malagelada, 1986; Sander and Publicover, 1994; Stern et al., 2007).

\section{Functional significance of the stomach-brain coherence}

The functional significance of the stomach-brain coherence is unclear and awaits to be established. Speculatively, this phenomenon is an indication of how the brain monitors the gut in real-time and regulates food intake and digestion (Holtmann and Talley, 2014). It might also indicate how the gut exerts interoceptive influences on brain and behaviors (Critchley and Harrison, 2013; Azzalini et al., 2019). To establish its functional significance, it is necessary to relate the stomach-brain coherence to behavior, such eating behavior, perceptual and cognitive performance. It would also be valuable to evaluate the stomach-brain coherence beyond normal conditions or healthy populations and explore its relationship to various symptoms in diseased conditions.

\section{Conclusion}

In healthy and anesthetized rats, spontaneous brain activity in the "gastric network" is coherent with the intrinsic slow wave from the stomach, consistent with recent findings from humans (Rebollo et al., 2018; Choe et al., 2021). This network involves a number of subcortical and cortical regions that span across the sensory, motor, and limbic systems. Importantly, the vagus nerve is the primary pathway that mediates the stomach-brain coherence. 
bioRxiv preprint doi: https://doi.org/10.1101/2022.01.25.477693; this version posted January 27,2022. The copyright holder for this preprint

(which was not certified by peer review) is the author/funder, who has granted bioRxiv a license to display the preprint in perpetuity. It is made available under aCC-BY-NC-ND 4.0 International license.

\section{Acknowledgement}

The authors thank Drs. John Furness, Terry Powley, Leo Cheng, Ulrich Scheven for their valuable discussions. This study is supported by the National Institutes of Health (OD023847, OD030538, AT011665), the University of Michigan, and Purdue University. 


\section{Reference}

Albin, R.L., Young, A.B. and Penney, J.B., 1989. The functional anatomy of basal ganglia disorders. Trends in neurosciences, 12(10), pp.366-375.

Andresen, M.C. and Kunze, D.L., 1994. Nucleus tractus solitarius-gateway to neural circulatory control. Annual review of physiology, 56(1), pp.93-116.

Azpiroz, F., \& Malagelada, J. R. (1987). Importance of vagal input in maintaining gastric tone in the dog. The Journal of Physiology, 384(1), 511-524.

Azzalini, D., Rebollo, I, Tallon-Baudry, C., Visceral signals shape brain dynamics and cognition.

Trends in Cognitive Neuroscience, 23(6): 488-509, 2019.

Electrogastrography, A.T.L., 1988. Current assessment and future perspectives/Th. L. Abell, JR Malagelada. Dig. Dis. Sci, 33(8), pp.982-992.

Babic, T. and Browning, K.N., 2014. The role of vagal neurocircuits in the regulation of nausea and vomiting. European journal of pharmacology, 722, pp.38-47.

Berthoud, H. R., and Powley, T. L. (1992). Vagal afferent innervation of the rat fundic stomach: morphological characterization of the gastric tension receptor. Journal of Comparative Neurology, 319(2), 261-276.

Bor, C., Bordin, D., Demirag, K. and Uyar, M., 2016. The effect of brain death and coma on gastric myoelectrical activity. Turk J Gastroenterol, 27(3), pp.216-220.

Borland, M.S., Vrana, W.A., Moreno, N.A., Fogarty, E.A., Buell, E.P., Sharma, P., Engineer, C.T. and Kilgard, M.P., 2016. Cortical map plasticity as a function of vagus nerve stimulation intensity. Brain stimulation, 9(1), pp.117-123.

Brandstaeter, S., Fuchs, S.L., Aydin, R.C. and Cyron, C.J., 2019. Mechanics of the stomach: A review of an emerging field of biomechanics. GAMM-Mitteilungen, 42(3), p.e201900001.

Brookes, S.J., Spencer, N.J., Costa, M. and Zagorodnyuk, V.P., 2013. Extrinsic primary afferent signalling in the gut. Nature reviews Gastroenterology \& hepatology, 10(5), pp.286-296. 
Browning, K.N. and Travagli, R.A., 2014. Central nervous system control of gastrointestinal motility and secretion and modulation of gastrointestinal functions. Comprehensive physiology, 4(4), p.1339.

Cajal, 1893. Sur les ganglions et plexus nerveux d'intestin. C R Soc Biol. 1893; 5: 217-23. Cao, J., Lu, K-H., Powley, T.L., Liu, Z., 2017. Vagal nerve stimulation triggers widespread responses and alters large-scale functional connectivity in the rat brain. PLoS ONE, 12(12): e0189518.

Cao, J., Lu, K.H., Oleson, S.T., Phillips, R.J., Jaffey, D., Hendren, C.L., Powley, T.L. and Liu, Z., 2019. Gastric stimulation drives fast BOLD responses of neural origin. Neurolmage, 197, pp.200-211.

Cao, J., Wang, X., Powley, T.L., Liu, Z., 2021. Gastric neurons in the nucleus tractus solitarius are selective to the orientation of gastric electrical stimulation. Journal of Neural Engineering, 18(5): 056066.

Chen, J.D.Z., Zou, X., Lin, X., Ouyang, S. and Liang, J., 1999. Detection of gastric slow wave propagation from the cutaneous electrogastrogram. American Journal of PhysiologyGastrointestinal and Liver Physiology, 277(2), pp.G424-G430.

Choe, A.S., Tang, B., Smith, K.R., Honari, H., Lindquist, M.A., Caffo, B.S. and Pekar, J.J., 2021. Phase-locking of resting-state brain networks with the gastric basal electrical rhythm. PloS one, 16(1), p.e0244756.

Clemmensen, C., Müller, T. D., Woods, S. C., Berthoud, H. R., Seeley, R. J., and Tschöp, M. H. (2017). Gut-brain cross-talk in metabolic control. Cell, 168(5), 758-774.

Collman, P. I., Grundy, D., Scratcherd, T., and Wach, R. A. (1984). Vago-vagal reflexes to the colon of the anaesthetized ferret. The Journal of physiology, 352(1), 395-402.

Craig, A.D., 2003. Interoception: the sense of the physiological condition of the body. Current opinion in neurobiology, 13(4), pp.500-505. 
Craig, A.D., 2005. Forebrain emotional asymmetry: a neuroanatomical basis?. Trends in cognitive sciences, 9(12), pp.566-571.

Craig, A.D., 2009. How do you feel--now? The anterior insula and human awareness. Nature reviews neuroscience, 10(1).

Davidson, T.L., Chan, K., Jarrard, L.E., Kanoski, S.E., Clegg, D.J. and Benoit, S.C., 2009. Contributions of the hippocampus and medial prefrontal cortex to energy and body weight regulation. Hippocampus, 19(3), pp.235-252.

Davidson, T.L., Kanoski, S.E., Schier, L.A., Clegg, D.J. and Benoit, S.C., 2007. A potential role for the hippocampus in energy intake and body weight regulation. Current opinion in pharmacology, 7(6), pp.613-616.

Deloose, E., Janssen, P., Depoortere, I. and Tack, J., 2012. The migrating motor complex: control mechanisms and its role in health and disease. Nature reviews Gastroenterology \& hepatology, 9(5), pp.271-285.

Engineer, C.T., Engineer, N.D., Riley, J.R., Seale, J.D. and Kilgard, M.P., 2015. Pairing speech sounds with vagus nerve stimulation drives stimulus-specific cortical plasticity. Brain stimulation, 8(3), pp.637-644.

Erişir, A., Van Horn, S. C., and Sherman, S. M. (1997). Relative numbers of cortical and brainstem inputs to the lateral geniculate nucleus. Proceedings of the National Academy of Sciences, 94(4),

Filogamo, G. and Gabella, G., 1970. EFFECTS OF EXTRINSIC DENERVATION ON SYNAPSES OF MYENTERIC PLEXUS. Journal de Microscopie, 9(2), pp.281-+. Furness, J.B., Di Natale, M., Hunne, B., Oparija-Rogenmozere, L., Ward, S.M., Sasse, K.C., Powley, T.L., Stebbing, M.J., Jaffey, D. and Fothergill, L.J., 2020. The identification of neuronal control pathways supplying effector tissues in the stomach. Cell and Tissue Research, pp.1-13. 
Furness, J. B., and Stebbing, M. J. (2018). The first brain: Species comparisons and evolutionary implications for the enteric and central nervous systems. Neurogastroenterology \& motility, 30(2), e13234.

Geeraerts, B., Van Oudenhove, L., Dupont, P., Vanderghinste, D., Bormans, G., Van Laere, K., and Tack, J. (2011). Different regional brain activity during physiological gastric distension compared to balloon distension: a H2150-PET study. Neurogastroenterology \& Motility, 23(6), 533-e203.

Geldof, H., Van der Schee, E.J., Van Blankenstein, M., Smout, A.J.P.M. and Akkermans, L.M.A., 1990. Effects of highly selective vagotomy on gastric myoelectrical activity. Digestive diseases and sciences, 35(8), pp.969-975.

Han, W., Tellez, L.A., Perkins, M.H., Perez, I.O., Qu, T., Ferreira, J., Ferreira, T.L., Quinn, D., Liu, Z.W., Gao, X.B. and Kaelberer, M.M., 2018. A neural circuit for gut-induced reward. Cell, 175(3), pp.665-678.

Konturek, S.J., Konturek, J.W., Pawlik, T., Brzozowki, T., Brain-gut axis and its role in the control of food intake. 2004. Journal of Physiology and Pharmacology, 55(1): 137-154.

Lu, K-H, Cao, J., Oleson, S.T., Ward, M.P., Phillips, R.L., Powley, T.L., Liu, Z., Vagus nerve stimulation promotes gastric emptying by increasing pyloric opening measured with magnetic resonance imaging, 2018. Neurogastroenterology and Motility, 30(10): e13380.

Liu, K-H, Cao, J., Phillips, R.J., Powley, T.L., Liu, Z., Acute effects of vagus nerve stimulation parameters on gastric motility assessed with magnetic resonance imaging, 2020, Neurogastroenterology and Motility, 32(7): e13853.

Harper, A. A., Kidd, C., \& Scratcherd, T. (1959). Vago-vagal reflex effects on gastric and pancreatic secretion and gastro-intestinal motility. The Journal of physiology, 148(2), 417.

Holtmann, G., and Talley, N. J. (2014). The stomach-brain axis. Best Practice \& Research Clinical Gastroenterology, 28(6), 967-979. 
Hurley-Gius, K. M., \& Neafsey, E. J. (1986). The medial frontal cortex and gastric motility: microstimulation results and their possible significance for the overall pattern of organization of rat frontal and parietal cortex. Brain research, 365(2), 241-248.

Kaelberer, M. M., Buchanan, K. L., Klein, M. E., Barth, B. B., Montoya, M. M., Shen, X., \& Bohórquez, D. V. (2018). A gut-brain neural circuit for nutrient sensory transduction. Science, 361(6408).

Lyubashina, O. A. (2004). Possible mechanisms of involvement of the amygdaloid complex in the control of gastric motor function. Neuroscience and behavioral physiology, 34(4), 379-388. Hamilton, J.W., Bellahsene, B.E., Reichelderfer, M., Webster, J.G. and Bass, P., 1986. Human electrogastrograms. Digestive diseases and sciences, 31(1), pp.33-39.

Hasler, W.L., Kim, M.S., Chey, W.D., Stevenson, V.E.R.N.O.N., Stein, B.R.U.C.E. and Owyang, C.H.U.N.G., 1995. Central cholinergic and alpha-adrenergic mediation of gastric slow wave dysrhythmias evoked during motion sickness. American Journal of Physiology-Gastrointestinal and Liver Physiology, 268(4), pp.G539-G547.

Holst, M.C., Kelly, J.B. and Powley, T.L., 1997. Vagal preganglionic projections to the enteric nervous system characterized with Phaseolus vulgaris-leucoagglutinin. Journal of Comparative Neurology, 381(1), pp.81-100.

Hurley-Gius, K.M. and Neafsey, E.J., 1986. The medial frontal cortex and gastric motility: microstimulation results and their possible significance for the overall pattern of organization of rat frontal and parietal cortex. Brain research, 365(2), pp.241-248.

Kanoski, S.E. and Grill, H.J., 2017. Hippocampus contributions to food intake control:

mnemonic, neuroanatomical, and endocrine mechanisms. Biological psychiatry, 81(9), pp.748756.

Klarer, M., Arnold, M., Günther, L., Winter, C., Langhans, W., \& Meyer, U. (2014). Gut vagal afferents differentially modulate innate anxiety and learned fear. Journal of Neuroscience, 34(21), 7067-7076. 
Klarer, M., Krieger, J. P., Richetto, J., Weber-Stadlbauer, U., Günther, L., Winter, C., Arnold, M., Langhans, W., \& Meyer, U. (2018). Abdominal vagal afferents modulate the brain transcriptome and behaviors relevant to schizophrenia. Journal of Neuroscience, 38(7), 1634-1647.

Klimesch, W., 2018. The frequency architecture of brain and brain body oscillations: an analysis. European Journal of Neuroscience, 48(7), pp.2431-2453.

KIM, C.H. and MALAGELADA, J.R., 1986, March. Electrical activity of the stomach: clinical implications. In Mayo Clinic Proceedings (Vol. 61, No. 3, pp. 205-210). Elsevier.

Koch, K.L., 2014. Gastric dysrhythmias: a potential objective measure of nausea. Experimental brain research, 232(8), pp.2553-2561.

Ladabaum, U. R. I., Minoshima, S., Hasler, W. L., Cross, D., Chey, W. D., and Owyang, C. (2001). Gastric distention correlates with activation of multiple cortical and subcortical regions. Gastroenterology, 120(2), 369-376.

Lai, J. and David, S.V., 2021. Short-term effects of vagus nerve stimulation on learning and evoked activity in auditory cortex. Eneuro.

Levinthal, D.J. and Strick, P.L., 2020. Multiple areas of the cerebral cortex influence the stomach. Proceedings of the National Academy of Sciences, 117(23), pp.13078-13083. Levinthal, D.J. and Strick, P.L., 2020. Multiple areas of the cerebral cortex influence the stomach. Proceedings of the National Academy of Sciences, 117(23), pp.13078-13083.

Liang, Z., King, J., Zhang, N., 2011. Uncovering intrinsic connectional architecture of functional networks in awake rat brain. Journal of Neuroscience, 31(10): 3776-3783.

Liang, Z., King, J., Zhang, N., 2012. Intrinsic organization of the anesthetized brain. Journal of Neuroscience, 32(30): 10183-10191.

Liu, Y., Perez, P.D., Ma, Z., Ma, Z., Dopfel, D., Cramer, S., Tu, W., Zhang, N., 2020. An open database of resting-state fMRI in awake rats. Neurolmage, 220: 117094.

Liu, Z., de Zwart, J.A., Yao, B., van Gerderen, P., Kuo, L-W, Duyn, J.H. Finding thalamic BOLD correlates to posterior alpha EEG. 2012. Neurolmage, 63(3), pp. 1060-1069. 
Lu, C. L., Wu, Y. T., Yeh, T. C., Chen, L. F., Chang, F. Y., Lee, S. D., ... and Hsieh, J. C. (2004).

Neuronal correlates of gastric pain induced by fundus distension: A 3T-fMRI study.

Neurogastroenterology \& Motility, 16(5), 575-587.

Mayer, E. A. (2011). Gut feelings: the emerging biology of gut-brain communication. Nature

Reviews Neuroscience, 12(8), 453-466.

Mayer, E. A., Labus, J., Aziz, Q., Tracey, I., Kilpatrick, L., Elsenbruch, S., ... and Borsook, D.

(2019). Role of brain imaging in disorders of brain-gut interaction: a Rome Working Team

Report. Gut, 68(9), 1701-1715.

Nakamura, T., Tanida, M., Niijima, A. and Nagai, K., 2009. Effect of auditory stimulation on

parasympathetic nerve activity in urethane-anesthetized rats. in vivo, 23(3), pp.415-419.

Ness, T.J., Gebhart, G.F., 1990. Visceral pain: a review of experimental studies. Pain, 41(2):

167-234.

Ouyang, C., 1996. Clinical significance of gastric dysrhythmias. World Journal of

Gastroenterology, 2(Suppl1), pp.5-6.

Parent, A. and Hazrati, L.N., 1995. Functional anatomy of the basal ganglia. II. The place of subthalamic nucleus and external pallidium in basal ganglia circuitry. Brain research reviews, 20(1), pp.128-154.

Pazo, J.H. and Belforte, J.E., 2002. Basal ganglia and functions of the autonomic nervous system. Cellular and molecular neurobiology, 22(5), pp.645-654.

Pierce, J.E. and Péron, J., 2020. The basal ganglia and the cerebellum in human emotion. Social Cognitive and Affective Neuroscience, 15(5), pp.599-613.

Papp, E. A., Leergaard, T. B., Calabrese, E., Johnson, G. A., and Bjaalie, J. G. (2014).

Waxholm Space atlas of the Sprague Dawley rat brain. Neuroimage, 97, 374-386.

Paxinos, G., and Watson, C. (2006). The rat brain in stereotaxic coordinates: hard cover edition. Elsevier. 
Pigarev, I., Almirall, H., Pigareva, M.L., Bautista, V., Sánchez-Bahillo, A., Barcia, C. and Herrero, M.T., 2006. Visceral signals reach visual cortex during slow wave sleep. Study in monkeys. Acta neurobiologiae experimentalis, 66(1), p.69.

Pigarev, I.N., 1994. Neurons of visual cortex respond to visceral stimulation during slow wave sleep. Neuroscience, 62(4), pp.1237-1243.

Pigarev, I.N., Bagaev, V.A., Levichkina, E.V., Fedorov, G.O. and Busigina, I.I., 2013. Cortical visual areas process intestinal information during slow wave sleep. Neurogastroenterology \& motility, 25(3), pp.268-e169.

Powley, T.L., Jaffey, D.M., McAdams, J., Baronowsky, E.A., Black, D., Chesney, L., Evans, C. and Phillips, R.J., 2019. Vagal innervation of the stomach reassessed: brain- gut connectome uses smart terminals. Annals of the New York Academy of Sciences, 1454(1), p.14.

Powley, T.L., 2021. Brain-gut communication: vagovagal reflexes interconnect the two "brains". American Journal of Physiology Gastrointestinal and Liver Physiology, doi: https://doi.org/10.1152/ajpgi.00214.2021.

Rebollo, I., Devauchelle, A.D., Béranger, B. and Tallon-Baudry, C., 2018. Stomach-brain synchrony reveals a novel, delayed-connectivity resting-state network in humans. Elife, 7 , p.e33321.

Rebollo, I., Wolpert, N., and Tallon-Baudry, C. (2021). Brain-stomach coupling: Anatomy, functions, and future avenues of research. Current Opinion in Biomedical Engineering, 100270. Rebollo, I., Tallon-Boudry, C., 2021. The sensory and motor components of the cortical hierarchy are coupled to the rhythm of the stomach during rest. Biorxiv preprint doi: https://doi.org/10.1101/2021.05.26.445829.

Richter, C.G., Babo-Rebelo, M., Schwartz, D. and Tallon-Baudry, C., 2017. Phase-amplitude coupling at the organism level: The amplitude of spontaneous alpha rhythm fluctuations varies with the phase of the infra-slow gastric basal rhythm. Neurolmage, 146, pp.951-958. 
Sanders, K.M. and Publicover, N.G., 1994. Excitation-contraction coupling in gastric muscles. Digestive diseases and sciences, 39(12), pp.69S-72S.

Rinaman, L., and Schwartz, G. (2004). Anterograde transneuronal viral tracing of central viscerosensory pathways in rats. Journal of Neuroscience, 24(11), 2782-2786.

Rogers, R. C., McTIGUE, D. M., and Hermann, G. E. (1995). Vagovagal reflex control of digestion: afferent modulation by neural and" endoneurocrine" factors. American Journal of Physiology-Gastrointestinal and Liver Physiology, 268(1), G1-G10.

Rogers, R. C., McTigue, D. M., and Hermann, G. E. (1996). Vagal control of digestion: modulation by central neural and peripheral endocrine factors. Neuroscience \& Biobehavioral Reviews, 20(1), 57-66.

Sanders, K.M., 1996. A case for interstitial cells of Cajal as pacemakers and mediators of neurotransmission in the gastrointestinal tract. Gastroenterology. 111: 492-515.

Sarna, S.K., 1985. Cyclic motor activity; migrating motor complex: 1985. Gastroenterology, 89(4), pp.894-913.

Shapiro, R. E., \& Miselis, R. R. (1985). The central organization of the vagus nerve innervating the stomach of the rat. Journal of Comparative Neurology, 238(4), 473-488.

Shetake, J.A., Engineer, N.D., Vrana, W.A., Wolf, J.T. and Kilgard, M.P., 2012. Pairing tone trains with vagus nerve stimulation induces temporal plasticity in auditory cortex. Experimental neurology, 233(1), pp.342-349.

Stephan, E., Pardo, J. V., Faris, P. L., Hartman, B. K., Kim, S. W., Ivanov, E. H., ... and Goodale, R. L. (2003). Functional neuroimaging of gastric distention. Journal of gastrointestinal surgery, $7(6), 740-749$.

Stern, R.M., Koch, K.L., Stewart, W.R. and Lindblad, I.M., 1987. Spectral analysis of tachygastria recorded during motion sickness. Gastroenterology, 92(1), pp.92-97. 
Stern, R., Koch, K., Levine, M., and Muth, E. (2007). Gastrointestinal Response. In J. Cacioppo,

L. Tassinary, and G. Berntson (Eds.), Handbook of Psychophysiology (pp. 211-230).

Cambridge: Cambridge University Press.

Stoddard, C.J., Smallwood, R., Brown, B.H. and Duthie, H.L., 1975. The immediate and delayed effects of different types of vagotomy on human gastric myoelectrical activity. Gut, 16(3), pp.165-170.

Takahashi, T., and Owyang, C. (1997). Characterization of vagal pathways mediating gastric accommodation reflex in rats. The Journal of physiology, 504(2), 479-488.

Thor, P.J., Gościński, I., Kolasińska-Kloch, W., Mądroszkiewicz, D., Mądroszkiewicz, E. and Furgała, A., 2003. Gastric myoelectric activity in patients with closed head brain injury. Medical Science Monitor, 9(9), pp.CR392-CR395.

Todd, J., Cardellicchio, P., Swami, V., Cardini, F. and Aspell, J.E., 2021. Weaker implicit interoception is associated with more negative body image: Evidence from gastric-alpha phase amplitude coupling and the heartbeat evoked potential. Cortex.

Travagli, R.A. and Anselmi, L., 2016. Vagal neurocircuitry and its influence on gastric motility. Nature Reviews Gastroenterology \& Hepatology, 13(7), pp.389-401.

Travagli, R.A., Hermann, G.E., Browning, K.N. and Rogers, R.C., 2006. Brainstem circuits regulating gastric function. Annu. Rev. Physiol., 68, pp.279-305.

Tümer, C., Oflazoğlu, H.D., Obay, B.D., Kelle, M. and Taşdemir, E., 2008. Effect of ghrelin on gastric myoelectric activity and gastric emptying in rats. Regulatory peptides, 146(1-3), pp.26-32. Tsurugizawa, T., Uematsu, A., Nakamura, E., Hasumura, M., Hirota, M., Kondoh, T., Uneyama, H. and Torii, K., 2009. Mechanisms of neural response to gastrointestinal nutritive stimuli: the gutbrain axis. Gastroenterology, 137(1), pp.262-273.

Uhlrich, D.J., Cucchiaro, J.B. and Sherman, S.M., 1988. The projection of individual axons from the parabrachial region of the brain stem to the dorsal lateral geniculate nucleus in the cat. Journal of Neuroscience, 8(12), pp.4565-4575. 
Valdes Hernandez, P. A., Sumiyoshi, A., Nonaka, H., Haga, R., Aubert Vasquez, E., Ogawa, T., Iturria-Medina, Y., Riera, J. J., and Kawashima, R. (2011). An in vivo MRI template set for morphometry, tissue segmentation, and fMRI localization in rats. Frontiers in neuroinformatics, $5,26$.

Vandenbergh, J., DuPont, P., Fischler, B., Bormans, G., Persoons, P., Janssens, J., and Tack, J. (2005). Regional brain activation during proximal stomach distention in humans: A positron emission tomography study. Gastroenterology, 128(3), 564-573.

Wang, G.J., Tomasi, D., Backus, W., Wang, R., Telang, F., Geliebter, A., Korner, J., Bauman, A., Fowler, J.S., Thanos, P.K. and Volkow, N.D., 2008. Gastric distention activates satiety circuitry in the human brain. Neuroimage, 39(4), pp.1824-1831.

Wang, G.J., Yang, J., Volkow, N.D., Telang, F., Ma, Y., Zhu, W., Wong, C.T., Tomasi, D., Thanos, P.K. and Fowler, J.S., 2006a. Gastric stimulation in obese subjects activates the hippocampus and other regions involved in brain reward circuitry. Proceedings of the National Academy of Sciences, 103(42), pp.15641-15645.

Wang, G.J., Yang, J., Volkow, N.D., Telang, F., Ma, Y., Zhu, W., Wong, C.T., Tomasi, D., Thanos, P.K. and Fowler, J.S., 2006b. Gastric stimulation in obese subjects activates the hippocampus and other regions involved in brain reward circuitry. Proceedings of the National Academy of Sciences, 103(42), pp.15641-15645.

Xu, L., Sun, X., Lu, J., Tang, M. and Chen, J.D.Z., 2008. Effects of gastric electric stimulation on gastric distention responsive neurons and expressions of CCK in rodent hippocampus. Obesity, 16(5), pp.951-957.

Xu, L., Sun, X., Tang, M. and Chen, J.D.Z., 2009. Involvement of the hippocampus and neuronal nitric oxide synapse in the gastric electrical stimulation therapy for obesity. Obesity surgery, 19(4), pp.475-483. 
Yin, J., Chen, J.D.Z., 2008. Roles of interstitial cells of Cajal in regulating gastrointestinal

motility: in vitro versus in vivo studies. Journal of Cellular and Molecular Medicine. 12(4): 1118-

1129.

Zagorodnyuk, V.P., Chen, B.N. and Brookes, S.J., 2001. Intraganglionic laminar endings are mechano-transduction sites of vagal tension receptors in the guinea-pig stomach. The Journal of physiology, 534(1), pp.255-268. 


\section{Figures}
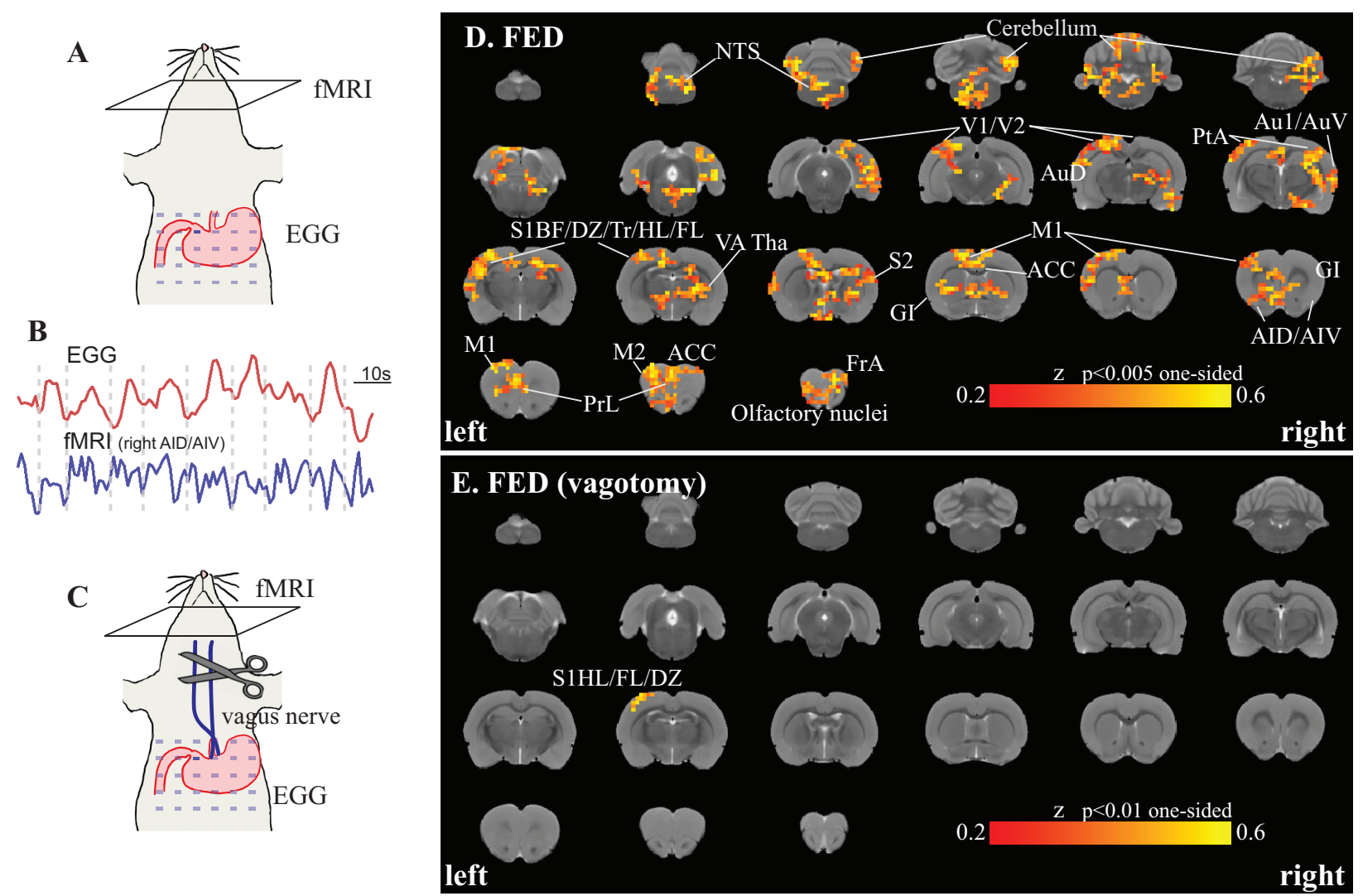

Figure 1. fMRI activity coherent with gastric slow waves. A \& C illustrate concurrent fMRI and EGG in two groups of rats after consuming a test meal with either intact vagus nerves (A) or bilateral cervical vagotomy (C). B shows an example EGG signal collected from xiphoid and the concurrent $\mathrm{fMRI}$ signal from one example region (right AID/AIV). The EGG and $\mathrm{fMRI}$ signals shown here demonstrate coherence between them at a low frequency around 5 CPM. D shows a map of voxels in which fMRI signals were significantly coherent with EGG (one-sided $p<0.005$, one-way t-test). EGG-coherent cortical and subcortical regions are labeled according to existing rat brain atlases (Paxinos \& Watson, 2006; Valdes Hernandez et al., 2011; Papp et al., 2014). E shows the EGG-coherent regions in animals with bilateral cervical vagotomy (one-sided $p<0.01$, one-way t-test). In both $\mathbf{C}$ and $\mathbf{E}$, the underlay shows the T2-weighted images in an existing rat brain MRI template (Valdes Hernandez et al., 2011). The abbreviated labels are explained as the 
following: ACC, anterior cingulate cortex; AID, agranular insular cortex, dorsal region; AIV, agranular insular cortex, ventral region; FrA, frontal association cortex; GI, granular insular cortex; M1, primary motor cortex; M2, secondary motor cortex; NTS, nucleus tractus solitarius; PrL, prelimbic cortex; PtA, parietal association cortex; S1BF, primary somatosensory cortex, barrel field; S1DZ, primary somatosensory cortex, dysgranular region; S1FL, primary somatosensory cortex, forelimb region; $\mathrm{S} 1 \mathrm{HL}$, primary somatosensory cortex, hindlimb region; S1Tr, primary somatosensory cortex, trunk region; S2, secondary somatosensory cortex; $\mathrm{V} 2$, secondary visual cortex; VATha, ventral anterior thalamic nucleus. 


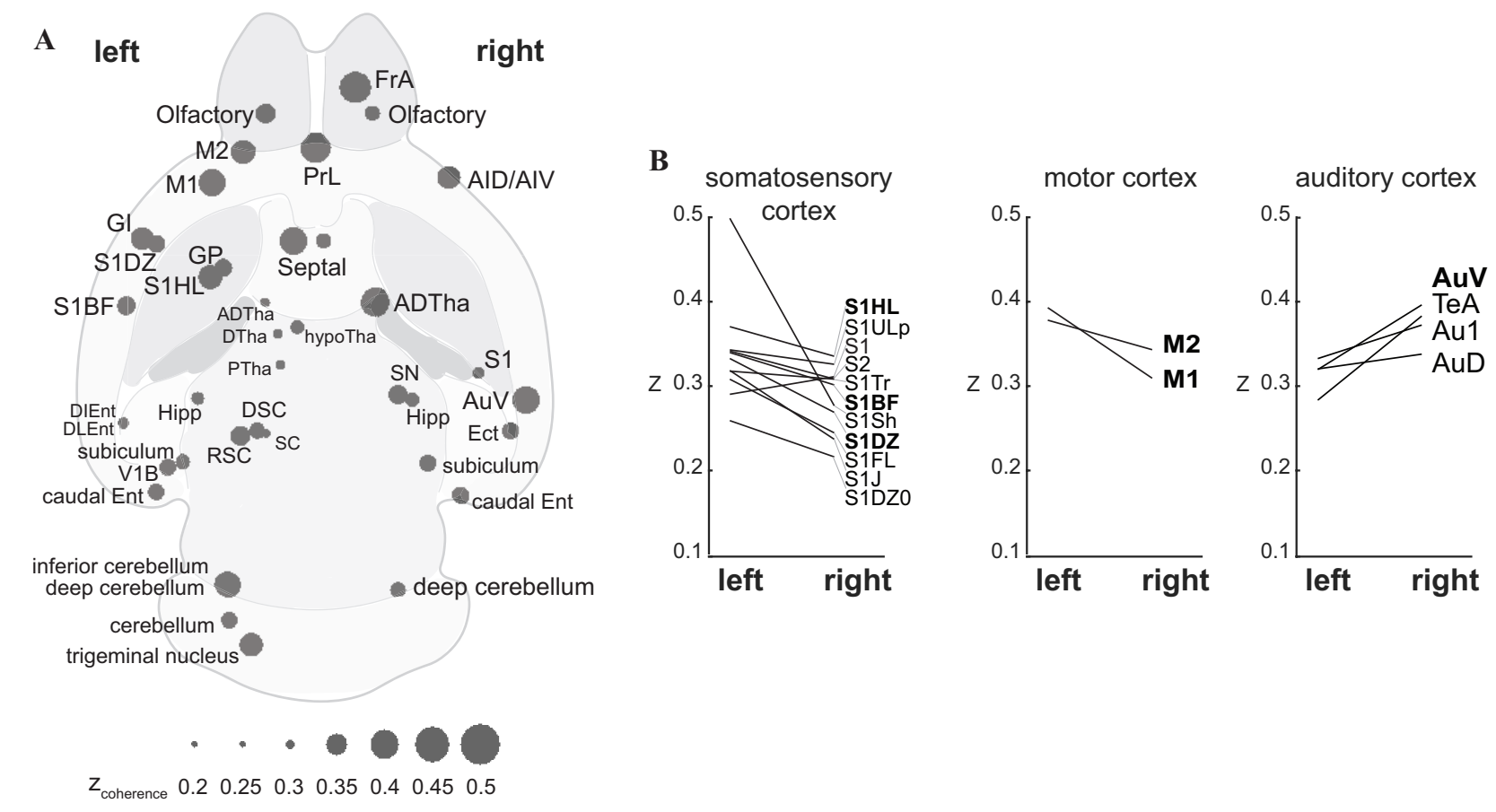

Figure 2. Lateralization of the gastric network. A plots the brain regions having significant phase-coupling between the stomach and the brain (one-sample t-test, bonferroni corrected $p<0.05)$. The statistical test was based on the averaged coherence in each region of interest. B shows the difference in phase-coupling with EGG between homologous ROls in the left vs. right hemispheres. Results for the ROIs in the somatosensory cortex, motor cortex, and auditory cortex are shown in three separate subplots shown in the left, middle, and right, respectively. ADTha, anterior dorsal thalamic nucleus; AID, agranular insular cortex, dorsal region; AIV, agranular insular cortex, ventral region; Au1, primary auditory cortex; AuD, secondary auditory cortex, dorsal area; AuV, secondary auditory cortex, ventral area; caudal Ent, caudal entorhinal field; DIEnt, dorsal-intermediate entorhinal field; DLEnt, dorsal-lateral entorhinal field; DSC, deep superior colliculus; DTha, dorsal thalamus; Ect, ectorhinal cortex; FrA, frontal association cortex; FrL, prelimbic cortex, GI, granular insular cortex; GP, globus pallidus; Hipp, hippocampus; hypoTha, hypothalamus; M1, primary motor cortex; M2, secondary motor cortex; Olfactory, olfactory bulb; PTha, posterior thalamus; RSC, retrosplenial cortex; S1, primary somatosensory cortex; S1BF, primary somatosensory cortex, barrel field; S1DZ, primary somatosensory cortex, 
bioRxiv preprint doi: https://doi.org/10.1101/2022.01.25.477693; this version posted January 27, 2022. The copyright holder for this preprint

(which was not certified by peer review) is the author/funder, who has granted bioRxiv a license to display the preprint in perpetuity. It is made available under aCC-BY-NC-ND 4.0 International license.

dysgranular region; S1FL, primary somatosensory cortex, forelimb region; S1HL, primary somatosensory cortex, hindlimb region; S1Sh, primary somatosensory cortex, shoulder region; S1ULp, primary somatosensory cortex, upper lip region; S2, secondary somatosensory cortex; SC, superior colliculus; septal, septal nucleus; SN, substantia nigra; V1B, primary visual cortex, binocular area. 
A. coherence difference (control - vagotomy)

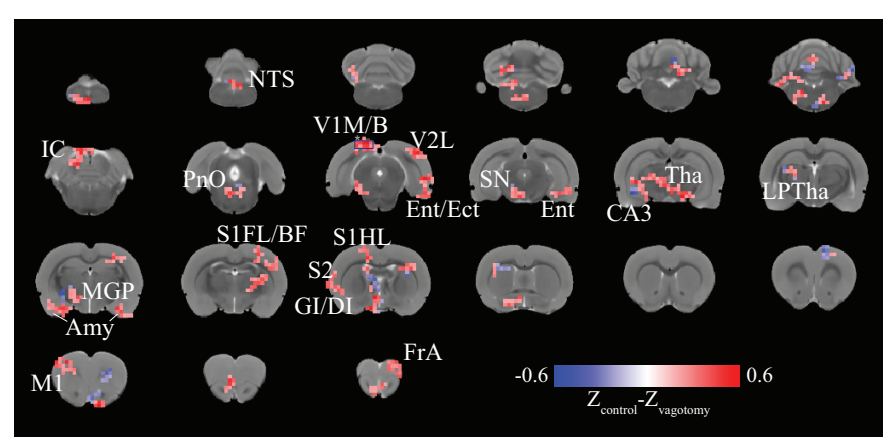

B.

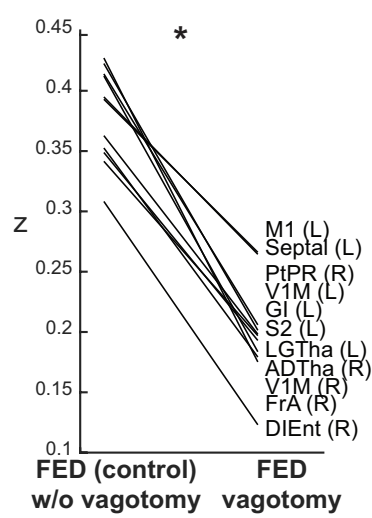

C.

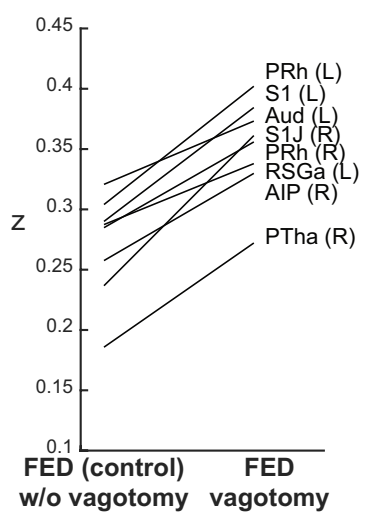

Figure 3. Vagal contributions to postprandial stomach-brain phase-coupling. A shows the voxel-level differences of coherence with a threshold of 0.25 between the control group (intact vagal nerves) and vagotomy at the fed state. B plots the ROI-level differences in phase coupling (quantified as $z$ scores) for regions where the coupling is stronger with the intact vagus than with vagotomy. The differences shown in this plot are statistically significant (two-way t-test, $\mathrm{p}<0.05$ ). Similarly, $\mathbf{C}$ plots the differences for the regions where the coupling is weaker with the intact vagus than with vagotomy, although the differences are not statistically significant. ADTha, anterior dorsal thatlmus; AIP, agranular insular cortex, posterior part; Amy, amygdala; Aud, secondary auditory cortex, dorsal area; CA3, field CA3 of hippocampus; DI, dysgranular insular cortex; DIEnt, dorsal-intermediate entorhinal field; Ect, ectorhinal cortex; Ent, entorhinal cortex; FrA, frontal association cortex; GI, granular insular cortex; IC inferior colliculus; LGTha, dorsal lateral geniculate nucleus; LPTha, lateral posterior thalamus; M1, primary motor cortex; MGP, medial globus pallidus; NTS, nucleus tractus solitarius; PnO, pontine reticular nucleus, oral part; PRh, perirhinal cortex; PTha, posterior thalamus; PtPD, dorsal posterior parietal cortex; PtPR, rostral posterior parietal cortex; RSGa, retrosplenial granular a cortex; S1, primary somatosensory cortex; S1BF, primary somatosensory cortex, barrel field; S1FL, primary somatosensory cortex, forelimb region; $\mathrm{S} 1 \mathrm{HL}$, primary somatosensory cortex, hindlimb region; $\mathrm{S} 1 \mathrm{~J}$, primary somatosensory cortex, jaw region; S2, secondary somatosensory cortex; septal, septal nucleus; 
bioRxiv preprint doi: https://doi.org/10.1101/2022.01.25.477693; this version posted January 27, 2022. The copyright holder for this preprint (which was not certified by peer review) is the author/funder, who has granted bioRxiv a license to display the preprint in perpetuity. It is made available under aCC-BY-NC-ND 4.0 International license.

$\mathrm{SN}$, substantia nigra; Tha, thalamus; V1B, primary visual cortex, binocular area; V1M, primary visual cortex, monocular area; V2L, secondary visual cortex, lateral area. 


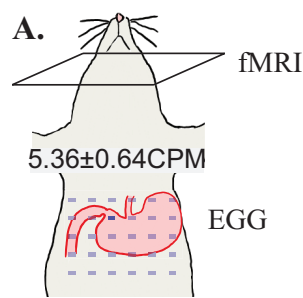

FED

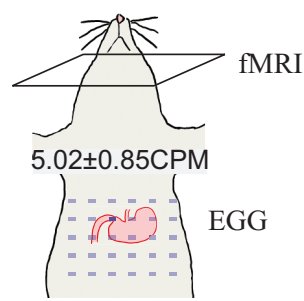

FASTED

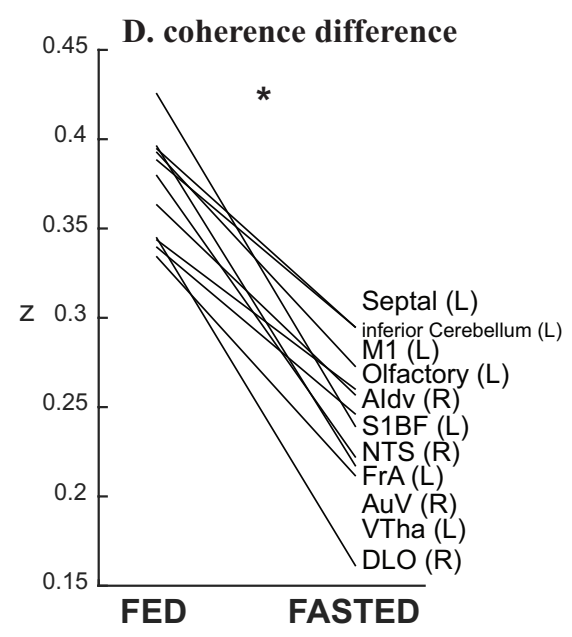

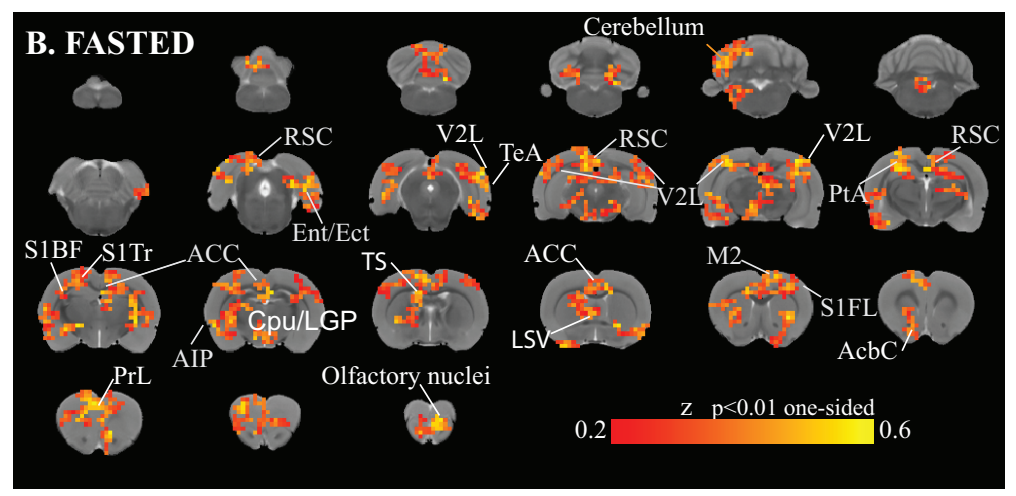

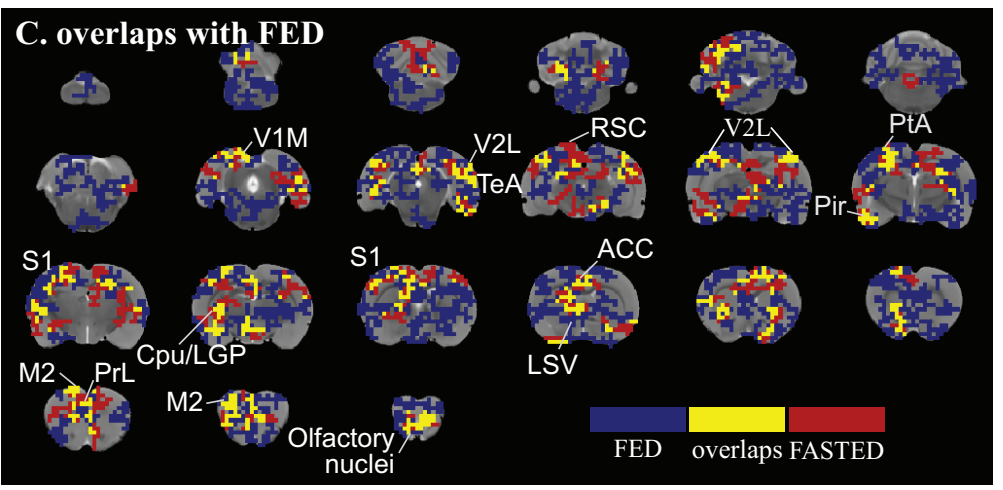

Figure 4. Stomach-brain phase coupling depends on the gastric state. A illustrates the fed vs. fasted state and shows the slow-wave frequency (meantstandard deviation) in each state. B shows the voxels in which fMRI signals are significantly coherent with EGG in the fasted state (one-sided $p<0.01$, t-test). C shows the overlapping voxels showing significant phase-coupling with EGG in both fasted and fed states with $p<0.01$. D plots the ROI-level differences in phasecoupling between the fed and fasted states, for the regions where such differences are statistically significant (t-test, $\mathrm{p}<0.05)$. AcbC, accumbens nucleus, core; ACC, anterior cingulate cortex; AIP, agranular insular cortex, posterior part; AuV, secondary auditory cortex, ventral area; Cpu, caudate putamen (striatum); DLO, dorsolateral orbital cortex; Ect, ectorhinal cortex; Ent, entorhinal cortex; FrA, frontal association cortex. LGP, lateral globus pallidus; LSV, lateral septal nucleus, ventral part; M2, secondary motor cortex; Pir, piriform cortex; PrL, prelimbic cortex; PtA, parietal association cortex; RSC, retrosplenial cortex; S1BF, primary somatosensory cortex, barrel field; S1FL, primary somatosensory cortex, forelimb region; S1Tr, primary somatosensory cortex, trunk region; TeA, temporal association cortex; TS, triangular septal nucleus; V1M, 
bioRxiv preprint doi: https://doi.org/10.1101/2022.01.25.477693; this version posted January 27, 2022. The copyright holder for this preprint (which was not certified by peer review) is the author/funder, who has granted bioRxiv a license to display the preprint in perpetuity. It is made available under aCC-BY-NC-ND 4.0 International license.

primary visual cortex, monocular area; V2L, secondary visual cortex, lateral area; VTha, ventral thalamus. 